are therefore expressed in the form of polynomials and the tangent planes to the resulting Gibbs energy surfaces are evaluated by computer. Modes of extrapolating the binary data into ternary ranges are being explored at present empirically. Among other examples, Spencer and Hayes (13) have estimated the excess Gibbs energies of liquid gold-silver-copper solutions by two such methods and shown them to agree rather well with the experimental results.

An example of a calculated phase boundary in a ternary system may be seen from Figure 4, in which the boundary of the miscibility gap in the system gold-palladium-platinum is compared with the experimental boundary at two temperatures (14). The agreement is admittedly modest, but shows the order of agreement that can be obtained at present. However, the development of the method is being quite energetically pursued by an international working group called CALPHAD ("Calculation of Phase Diagrams"), which is not unexpectedly working on alloyed steels and similar alloys of wide technological importance but can handle any ternary or even higher system for which sufficient basic thermochemical data are accurately known.

Thus, with some encouragement from those interested in the noble metals and their alloys, the application of chemical thermodynamics to the development of these materials could be considerably extended.

\section{References}

1 G. Ondracek and H. Wedemeyer, "Freie Bildungsenthalpien \& Metall-Keramik Wechselwirkungen", Inst. f Material- u. Festkörperforschung, Kernforschungszentrum Karlsruhe (1974)

2 T. Rosenqvist, Private Communication, February 1975

3 O. Kubaschewski and G. Heymer, Trans. Farad. Soc., 1960, 56, 473

4 P. S. Rudman, J. Stringer and R. I. Jaffee (Ed.), "Phase Stability in Metals and Alloys", Battelle Mem. Inst. Coll., Geneva \& Villars, 1967

5 R. Hultgren et al., "Selected Values of Thermodynamic Properties of Metals and Alloys", Wiley, 1974

6 C. B. Alcock and P. Grieveson, 7. Inst. Metals, 1962, 90, 304

7 K. C. Mills, "Thermodynamic Data for Inorganic Sulphides, Selenides \& Tellurides", Butterworths, 1974

8 O. Kubaschewski, Z. Elektrochem., 1943, 49, 446

9 O. Kubaschewski, Platinum Metals Rev., 1971, 15, 134

10 O. Kubaschewski and I. Barin, Pure \& Appl. Chem., 1974, 38, 469

11 B. Predel and D. W. Stein, Z. Naturforsch., 1971, 26a, 722

12 C. Wagner, Acta Metall, 1954, 2, 242

13 P. J. Spencer, F. H. Hayes and O. Kubaschewski, Rev. Chim. Minér., 1972, 9, 13

14 O. Kubaschewski and J. F. Counsell, Monatsh. Chemie, $1971,102,1724$

15 O. Kubaschewski and C. B. Alcock, "Metallurgical Thermochemistry", 4th Ed., Pergamon, 1967

16 B. Predel and H. Ruge, Z. Metallkunde, 1972, 63, 59

17 B. Predel and D. W. Stein, Acta Metall., 1972, 20, 681

18 B. Predel and E. Zehnpfund, Thermochimica Acta, 1974, 8,283

19 B. Predel and E. Zehnpfund, Z. Metallkunde, 1973, 64, 782

\title{
Improvements in Gold Extraction Metallurgy
}

For many years the level of extraction of gold from most ores of the Witwatersrand has been consistently above 95 per cent, so that any possible improvements in recovery must be marginal and limited to the few per cent now left in the residues from the various types of metallurgical circuits. These amount to only some 0.2 to 0.8 grams per tonne of ore, but recent research investigations by the South African mining industry and by the National Institute for Metallurgy have begun to show some worth-while means of increasing overall recovery.

These developments were reviewed in a paper presented to the annual meeting of the Metallurgical Society of the A.I.M.E. in New York by Dr. P. A. Laxen, Chief Scientist to the National Institute for Metallurgy.

The gold reefs in the Witwatersrand contain also uranium and pyrite, and some of the improvements to the standard gold extraction process have been associated with the recovery or concentration of one or both of these. A "reverse-leach" process, for example, in which acid treatment for the extraction of uranium precedes cyanidation, has been found to increase gold recovery by exposing the gold in acid-soluble minerals such as uraninite and in partly soluble silicates. Flotation prior to reverse leaching is used most successfully at one mine as a preconcentration procedure. Approximately 80 per cent of the gold, 25 per cent of the uranium and over 80 per cent of the sulphur report in the flotation concentrate, which is about 3 per cent of the weight of the ore. Gravity concentration, which is still widely used, is also the focal point of renewed interest on a number of mines, the trend being towards bulk rougher concentrates for maximum recovery.

Considerable attention is also being given to the application of concentration procedures to both current and past residues. Flotation of some current residues, for example in which thucolite is an important carrier of residual gold, appears justifiable. Some of the host minerals for uranium and gold are feebly magnetic, and wet high-intensity magnetic separation has also given promising results in both laboratory and pilot plant scale for uranium and gold recovery.

Flotation is reported as the method being considered by the Anglo-American Corporation for retreatment of one million tons of residues a month on the East Rand. The pyrite, which will be used for manufacture of sulphuric acid, and the recovered gold, are the justification for the undertaking.

Improvements in cyanidation have resulted from a closer study of operating variables such as the $\mathrm{pH}$ values and temperatures of the pulps, with continuous monitoring of the cyanide concentration, and this has again led to greater recovery.

Research in the Chamber of Mines laboratories is being carried out on the use of solvent extraction and ion exchange for the recovery of gold from solution. 